\title{
RANCANG BANGUN KURSI RODA ELEKTRIK BERBASIS INTERNET OF THINGS (IOT)
}

\author{
Chrissando Mayort Sailana ${ }^{1)}$, Tan Suryani Sollu ${ }^{2)}$, Alamsyah ${ }^{3)}$ \\ ${ }^{2,3)}$ Dosen Teknik Elektro Universitas Tadulako \\ Program Studi S1 Teknik Elektro, Fakultas Teknik, Universitas Tadulako \\ Jl. Soekarno Hatta Km. 9 Telp : (0451) 422611 - 422355 Fax : (0451) 422844 \\ E-mail : chrissandosailana@untad.ac.id
}

\begin{abstract}
Wheelchairs are mobility devices that are often used by people who have difficulty walking on their feet, due to illness, injury, or disability. Most of the wheelchairs that exist today are still using the manual system. Ideally, a wheelchair is needed so that users feel free and comfortable in adjusting the wheelchair movement according to their wishes.

This study aims to make an innovation in the form of designing an electric wheelchair based on the internet of things (IoT). In this tool, there are several integrated electronic components such as NodeMCU, voltage sensor that is connected to the android smartphone application. Delphi XE8 software functions to create control applications that can be controlled via a smartphone. The control system on a smartphone uses an internet connection to process the wheelchair control system. This tool is very dependent on the connection and stability of the internet network.

Design of electric wheelchair based IoT, has the performance that a wheelchair can carry a maximum load of $30 \mathrm{~kg}$ at a speed of $0.79 \mathrm{~m} /$ second, plus an accumulator / battery load and a $6.4 \mathrm{~kg}$ DC motor, so that the total load can be under of $36.4 \mathrm{~kg}$.
\end{abstract}

Keywords: NodeMCU, IoT, Voltage Sensor, Wheel Chair, Delphi XE8

\section{PENDAHULUAN}

Kursi roda merupakan alat mobilitas yang sering digunakan oleh orang yang mengalami kesulitan berjalan menggunakan kaki, disebabkan oleh penyakit, cedera, maupun cacat [1]. Idealnya kursi roda yang dibutuhkan agar pengguna merasa bebas dan nyaman dalam mengatur gerakan kursi roda sesuai kehendaknya. Kenyatannya hal tersebut tidak dapat dilakukan oleh pengguna yang memiliki keterbatasan pada bagian tangan [2], sehingga membutuhkan orang lain untuk dapat menggerakkan kursi roda tersebut. Oleh karena itu untuk mengatasi permasalahan tersebut diperlukan sebuah alat yang dapat membantu [3] dan mempermudah pengguna kursi roda yang dapat dengan mudah dikendalikan oleh pengguna atau pemakai, tanpa harus bersentuhan secara langsung dengan kursi roda yaitu kursi roda elektrik [4] berbasis IoT [5].

\section{METODE PENELITIAN}

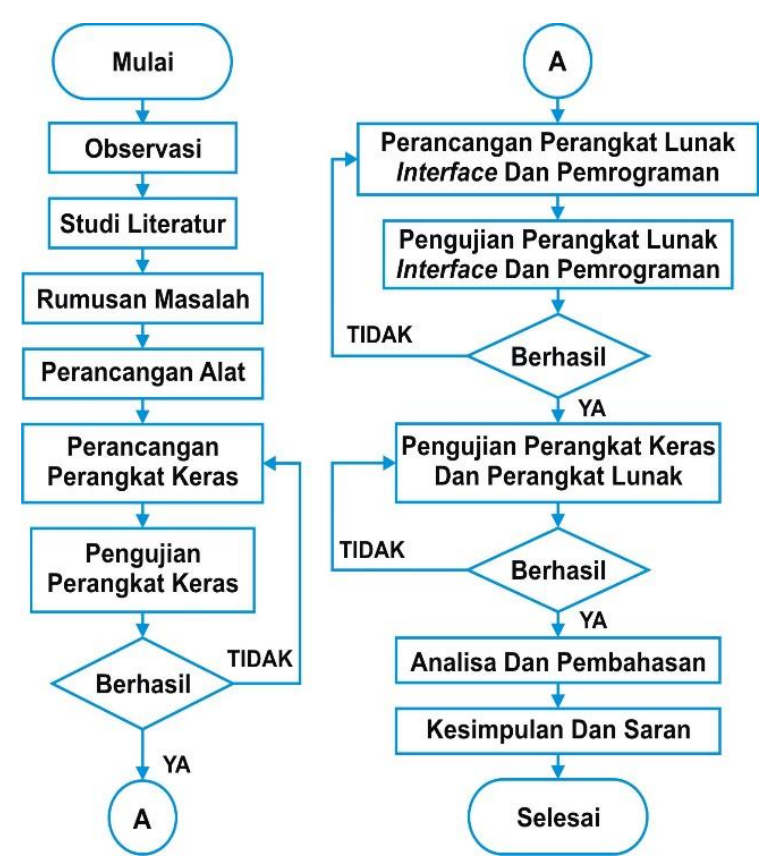

Gambar 1. Flowchart penelitian

Gambar 1 menunjukkan tahapan penelitian yang dimulai dari observasi, studi literatur, perancangan perangkat keras dan lunak, pengujian perangkat keras dan lunak, dan analisis.

\subsection{Observasi}

Langkah ini bertujuan untuk memastikan apakah tujuan dari penelitian diatas sudah sesuai atau tidak dengan kondisi yang ada 
dilapangan. Apabila sesuai, maka penelitian tersebut akan dilanjutkan ke tahap berikutnya.

\subsection{Studi Literatur}

Langkah ini bertujuan untuk mendapatkan data dan informasi pendukung yang lebih akurat tentang penelitian dan pembuatan alat yang telah dilakukan. Adapun sumber data yang diperoleh meliputi buku teks, jurnal, artikel, internet, dan pengumpulan data melalui wawancara dengan pengelola layanan kesehatan di rumah sakit.

\subsection{Perancangan Alat}

Tahap perancangan alat dilakukan setelah semua langkah-langkah tahapan observasi dan studi literatur telah dilakukan. Perancangan alat ini meliputi diagram blok perancangan alat, desain rencana penempatan alat dan flowchart sistem kerja alat.

Pada perancangan alat ini dapat digambarkan dalam bentuk blok diagram seperti berikut ini.

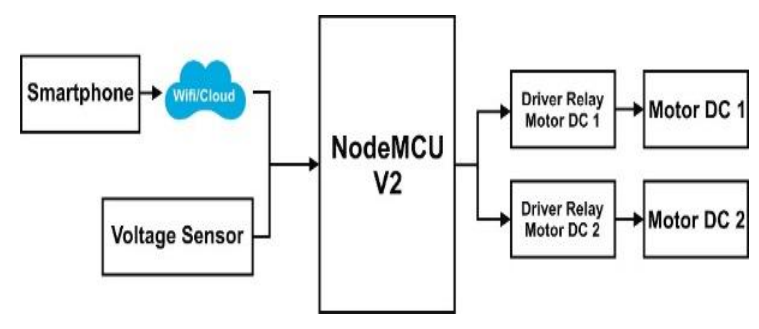

Gambar 2. Diagram blok perancangan alat

Pada Gambar 2 menunjukkan tiga tahapan yang meliputi unit masukan (input), unit proses, dan unit keluaran (output). Pada unit masukan menggunakan komponen yang terdiri dari smartphone sebagai remot kontrol dan voltage sensor sebagai pembaca data tegangan akumulator/aki. Pada unit proses menggunakan komponen board NodeMCU. Sedangkan unit keluaran menggunakan motor DC dan informasi jumlah tegangan dari voltage sensor ke aplikasi smartphone.

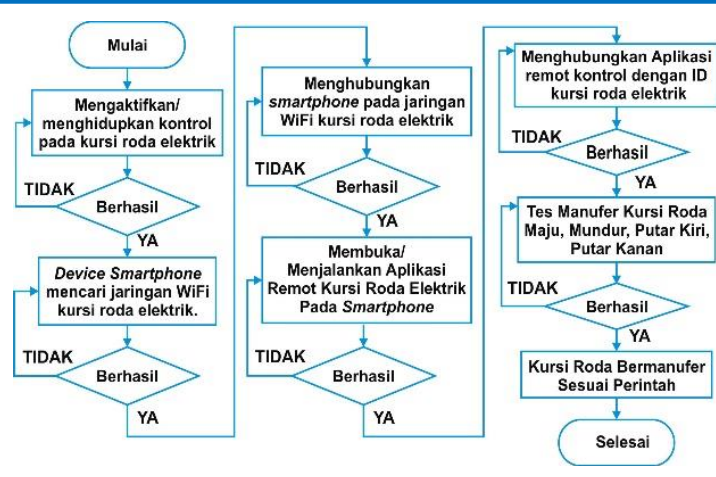

Gambar 3. Flowchart sistem kerja alat

Gambar 3 menunjukan sistem kerja alat, mulai dari menghidupkan kontrol pada kursi roda dan menghubungkan smartphone dengan jaringan WiFi yang disediakan board NodeMCU sampai dengan membuka atau menjalankan aplikasi remot kontrol [6] kursi roda elektrik [7]. Pengontrolan alat ini akan berfungsi apabila perangkat antara smartphone dan NodeMCU sudah terkoneksi atau terhubung dengan baik. Smartphone berperan penting sebagai remot kontrol pergerakan kursi roda.

\subsubsection{Perancangan Perangkat Keras}

Perangkat keras yang digunakan sebagai bahan untuk melakukan penelitian ini meliputi: kursi roda, board NodeMCU [8], motor DC, modul step down LM2596 [9], papan PCB (Printed Circuit Board), akumulator/aki, tombol/saklar, voltage sensor [10], relay 12 VDC, dan relay 5K 12 VDC 40A.

\subsubsection{Perancangan Perangkat Lunak}

Tahapan perancangan perangkat lunak dimulai dari pembuatan listing program untuk mengontrol kursi roda menggunakan bahasa pemrograman C pada arduino IDE. Setelah pembuatan listing program dilanjutkan dengan menghubungkan antara pemrograman arduino IDE ke sistem kontrol aplikasi program delphi XE8 [11]. Fungsi dari pembuatan interface pada delphi untuk menampilkan panel remot kontrol kursi roda dan informasi tegangan yang ada pada kursi roda.

\subsection{Pengujian Perangkat Keras dan Lunak}

Proses pengujian perangkat keras dan lunak dilakukan secara bertahap diawali dengan pengujian kinerja masing-masing perangkat keras. Pengujian perangkat keras 
dilakukan dengan cara mengukur dan mengamati perubahan keluaran rangkaian berdasarkan masukan yang diberikan. Selanjutnya dilanjutkan dengan pengujian perangkat lunak. Pengujian ini dimulai dengan melakukan konektifitas antara perangkat keras (NodeMCU) dan lunak (aplikasi smartphone). Setelah perangkat dapat terhubung maka dilanjutkan dengan pengujian listing program.

\subsection{Analisis dan Pembahasan}

Analisis dan pembahasan dilakukan apabila semua hasil perancangan dan pembuatan alat telah sesuai dengan yang diharapkan. Data yang akan di analisis yaitu tegangan catu daya motor DC, data pembacaan sensor tegangan, respond time NodeMCU, pengujian aplikasi android, dan data secara keseluruhan yang meliputi jumlah beban dan jarak komunikasi antara kursi roda dan remot kontrol. Setelah melakukan analisis, maka dilakukan lagi pembahasan yang sesuai dengan hasil dari analisis dan hasil dari langkahlangkah diatas sebelumnya.

\section{HASIL DAN PEMBAHASAN}

Dari hasil perancangan dan penelitian yang berjudul Rancang Bangun Kursi Roda Elektrik Berbasis Internet Of Things (IoT), maka dapat diperoleh hasil dalam bentuk fisik berupa alat, data tabel, dan hasil analisis data. Adapun hasil perancangan dan penelitian tersebut sebagai berikut.

\subsection{Bentuk Fisik Alat}

Rancang bangun kursi roda elektrik berbasis internet of things (IoT) dirancang menggunakan ukuran standard kursi roda pada umumnya, yang telah terpasang beberapa kotak tempat komponen elektronik dan juga terdapat 2 (dua) buah motor DC sebagai penggerak kursi roda elektrik.

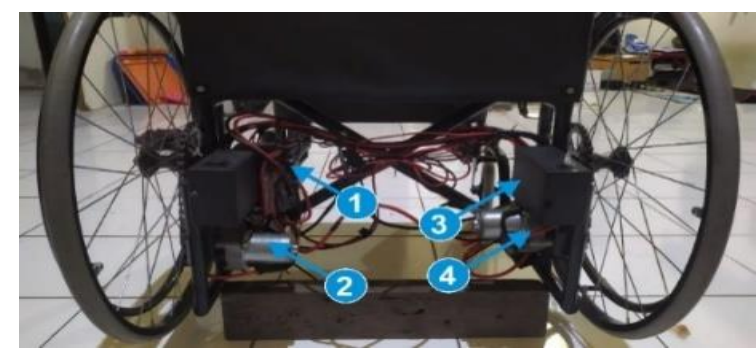

(a). Rancangan kursi roda tampak belakang

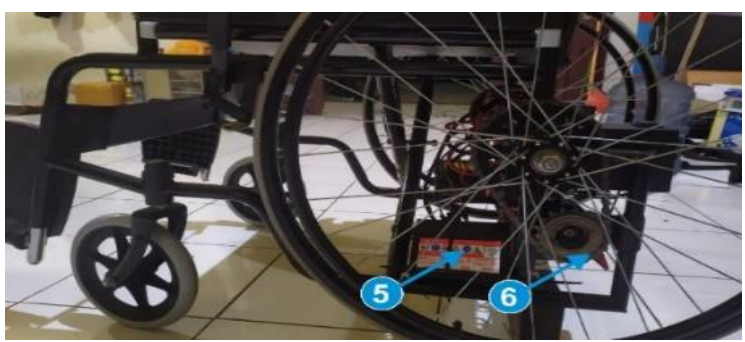

(b). Rancangan kursi roda tampak samping

Gambar 4. Rancangan kursi roda tampak belakang dan tampak sampaing

Keterangan: 1) Terminal penghubung kabel, 2) Motor DC 1, 3) Kotak Kontroler: NodeMCU V2, Sensor Tegangan, Driver Relay 12 VDC, 4) Motor DC 2, 5) Akumulator/Aki, dan 6) Gear box.

\subsubsection{Mikrokontroler dan Penggunaannya}

Pada penelitian ini, NodeMCU V2 digunakan sebagai board mikrokontroller yang telah dilengkapi system on chip ESP8266 yang berfungsi sebagai pengolah dan pengendali, baik sebagai penerima data (input) atau sebagai pemberi data (output). Penggunaan input pada NodeMCU tersebut antara lain sensor tegangan dan remot kontrol yang diakses menggunakan smartphone dan melalui cloud sebagai proses pengiriman data. Sedangkan penggunaan output pada NodeMCU antara lain adalah motor DC dan informasi berupa data jumlah tegangan pada aplikasi smartphone.

Input perintah menggunakan pengiriman data dari aplikasi pada smartphone, serta penggunaan komponen voltage sensor (sensor tegangan) menggunakan pin A0. Sedangkan, untuk rangkaian output seperti driver relay menggunakan pin digital D3, D4, D5, dan D6 pada board NodeMCU. Sedangkan komunikasi antara NodeMCU dengan aplikasi pada smartphone sebagai remot kontrol melalui komunikasi $\mathrm{WiFi}$. 


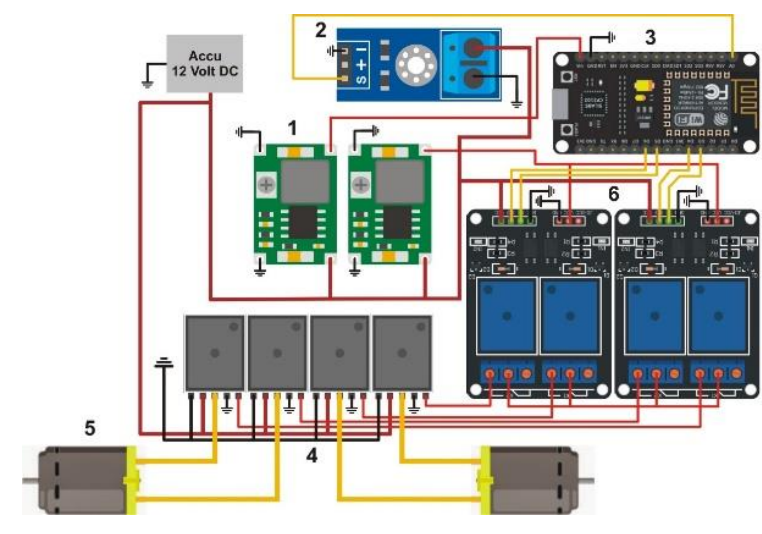

Gambar 5. Skematik rangkaian

Keterangan: 1) Step Down DC to DC, 2) Sensor tegangan, 3) NodeMCU V2, 4) Relay 5K 12 VDC, 5) Motor DC, dan 6) Driver Relay 12 VDC.

\subsubsection{Rangkaian Power Supply}

Power supply yang digunakan untuk memberikan suplay daya pada kursi roda elektrik ini yaitu berupa akumulator/aki 12 VDC dengan arus 3.5 A dirangkai paralel 2 (dua) buah sehingga dapat menghasilkan arus 7 A, yang kemudian dimasukan ke 2 (dua) buah modul step down DC-DC LM2596 menjadi tegangan 5 VDC. Modul step down pertama digunakan untuk menyalurkan tegangan pada mikrokontroler NodeMCU ESP8266, dan untuk modul step down kedua digunakan untuk menyalurkan tegangan pada relay. Gambar 6 menampilkan rangkaian power suplay yang digunakan pada kursi roda elektrik.

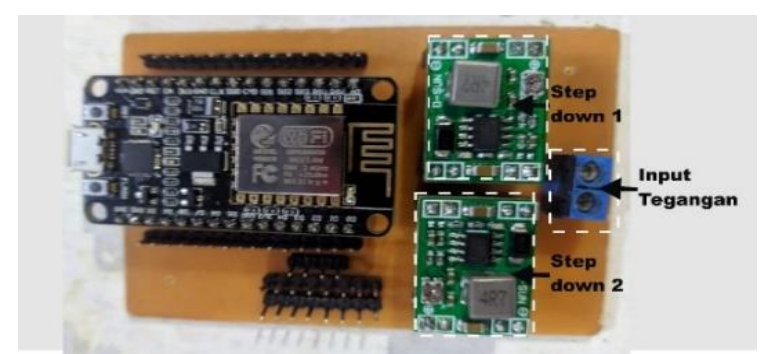

Gambar 6. Rangkaian power supply

\subsubsection{Rangkaian Relay}

Pada perancangan kursi roda elektrik menggunakan 2 (dua) model relay, model relay pertama yaitu terdiri atas 2 (dua) modul relay 12 VDC $2 \mathrm{CH}$ (channel) yang dapat dilihat pada Gambar 7. Modul relay 12 VDC 2 $\mathrm{CH}$ ini digunakan sebagai saklar untuk menghubungkan atau memutuskan tegangan 12 VDC pada model relay kedua. Model relay kedua menggunakan 4 (empat) relay $5 \mathrm{~K}$ yang biasanya digunakan pada klakson mobil, model relay kedua ini merupakan relay yang bekerja pada tegangan 12 VDC 40A, dapat dilihat pada Gambar 8. Relay ini yang digunakan untuk menghubungkan atau memutuskan tegangan pada motor DC.

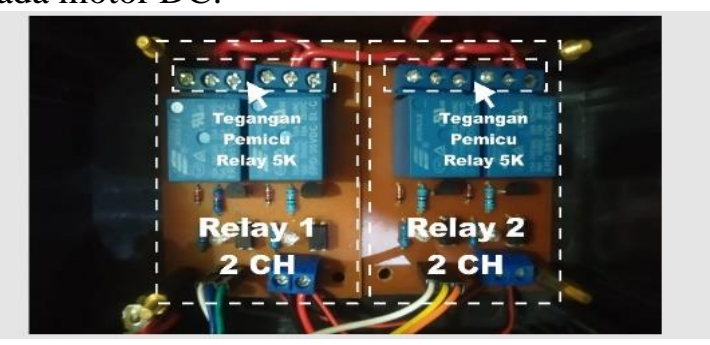

Gambar 7. Rangkaian relay 12 VDC

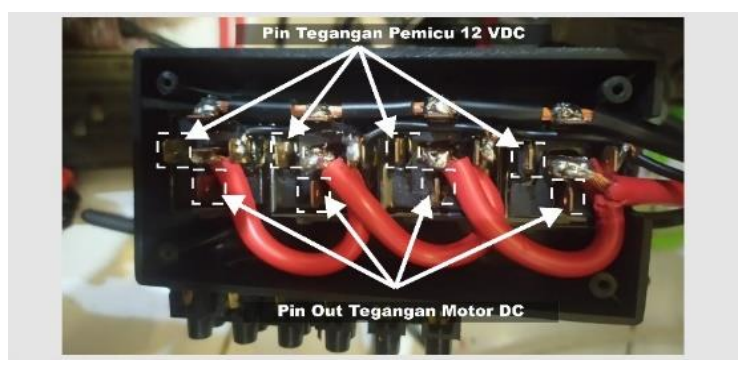

Gambar 8. Rangkaian relay 5K 12 VDC 40A

\subsubsection{Modul Voltage Sensor}

Modul voltage sensor atau modul sensor tegangan digunakan pada kursi roda elektrik untuk mengetahui nilai tegangan dari power suplay. Pembacaan nilai pada tegangan ini dimaksudkan untuk mengetahui tegangan kerja maksimal dan tegangan kerja minimal yang dapat digunakan untuk mengoperasikan kursi roda elektrik ini. Sensor tegangan ini dapat membaca tegangan hingga $25 \mathrm{VDC}$, pin $S$ pada modul ini digunakan sebagai pembacaan nilai analog yang dihubungkan ke pin A0 pada NodeMCU. Dibawah ini adalah gambar modul voltage sensor yang terpasang pada kursi roda elektrik.

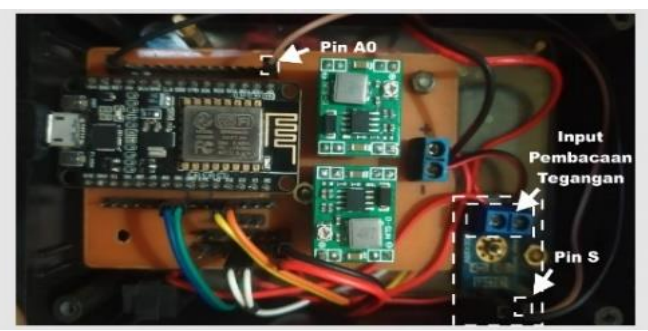

Gambar 9. Rangkaian modul voltage sensor pada kursi roda elektrik 


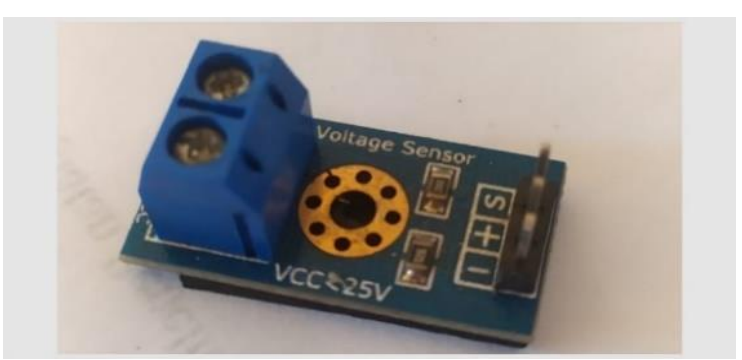

Gambar 10. Modul voltage sensor

\subsubsection{Software Aplikasi Remot Kontrol pada Smartphone}

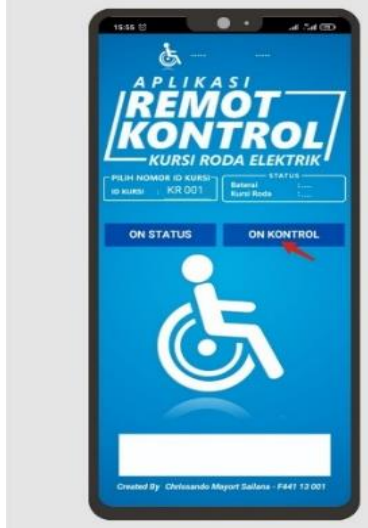

(a) Tampilan Awal

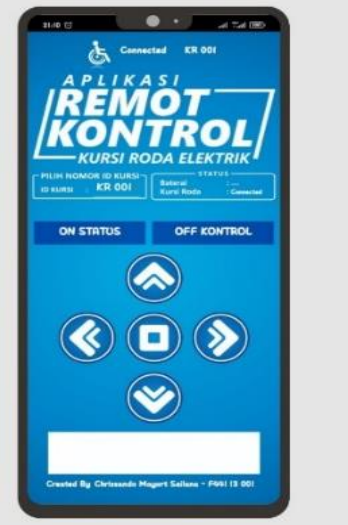

(b) Tampilan "ON KONTROL"
Gambar 11. Tampilan aplikasi remot kontrol kursi roda elektrik pada smartphone

Software aplikasi yang dibuat menggunakan Delphi XE8 bertujuan sebagai interface remot kontrol kursi roda elektrik antara NodeMCU dengan smartphone. Fungsi utama dari aplikasi ini adalah sebagai remot kontrol pergerakan kursi roda elektrik, dan juga sebagai interface tegangan pada kursi roda elektrik.

\subsection{Pengujian Alat}

Pengujian alat dilakukan dengan tujuan untuk mengetahui apakah alat yang telah dibuat berfungsi dengan baik sesuai dengan sistem yang direncanakan atau belum.

Pada penelitian tersebut, dilakukan percobaan beberapa kali dalam waktu yang berbeda-beda. Hal ini dilakukan untuk melihat tingkat keberhasilan pembacaan data tegangan dan juga pengontrolan menggunakan remot pada smartphone. Data tersebut diambil dari proses kinerja kursi roda saat dilakukan pengontrolan pergerakan kursi roda tersebut.
Pada pengujian alat secara keseluruhan maka dapat diperoleh hasil dalam bentuk fisik berupa alat, dan data tabel. Sehingga, dapat menjadi tolak ukur untuk meganalisis sistem yang telah dibuat secara keseluruhan.

\subsubsection{Pengujian tegangan catu daya motor DC \\ Driver motor relay berfungsi untuk} memutuskan dan menghubungkan tegangan dari catu daya ke motor DC. Pengujian ini ditujukan untuk mengetahui tegangan yang digunakan oleh motor DC kiri dan motor DC kanan. Pengujian dilakukan dengan menggunakan catu daya akumulator/aki.

Perhitungan persentase nilai selisih untuk mengetahui selisih penggunaan konsumsi tegangan antara motor kanan dan motor kiri dapat dihitung dengan cara, yaitu :

$$
\frac{(\text { Vout Motor Kanan })-(\text { Vout Motor Kiri })}{(\text { Vout Motor Kanan })} \times 100 \%
$$

Perhitungan selisih persentase secara keseluruhan dapat dilihat pada Tabel 1 , sebagai berikut.

Tabel 1. Pengujian tegangan catu daya motor DC

\begin{tabular}{|c|c|c|c|c|c|}
\hline \multirow[b]{2}{*}{ No. } & \multirow[b]{2}{*}{ Pengujian } & \multirow[b]{2}{*}{$\begin{array}{l}\text { Vin } \\
\text { (Volt) }\end{array}$} & \multicolumn{2}{|c|}{ Vout (Volt) } & \multirow[b]{2}{*}{$\begin{array}{c}\text { Selisih } \\
(\%)\end{array}$} \\
\hline & & & $\begin{array}{l}\text { Motor } \\
\text { Kanan } \\
(V m 1)\end{array}$ & $\begin{array}{c}\text { Motor } \\
\text { Kiri } \\
(V m 2)\end{array}$ & \\
\hline \multirow{3}{*}{1.} & \multirow{3}{*}{$\begin{array}{l}\text { Tanpa } \\
\text { beban }\end{array}$} & 12.67 & 7.10 & 6.56 & 7.60 \\
\hline & & 12.50 & 5.37 & 5.68 & 5.77 \\
\hline & & 12.41 & 5.69 & 5.71 & 0,35 \\
\hline \multirow{3}{*}{2.} & \multirow{3}{*}{$\begin{array}{c}\text { Dengan } \\
\text { beban }\end{array}$} & 12.26 & 4.23 & 3.46 & 18,2 \\
\hline & & 11.89 & 3,92 & 4.20 & 7,14 \\
\hline & & 11.56 & 3.53 & 3.68 & 4,24 \\
\hline
\end{tabular}

\subsubsection{Pengujian Sensor Tegangan}

Sensor tegangan berfungsi untuk membaca jumlah tegangan pada kursi roda elektrik. Pengujian sensor tegangan dilakukan dengan cara membandingkan pembacaan multimeter (pengukuran secara manual) dan pembacaan sensor tegangan pada aplikasi smartphone. 


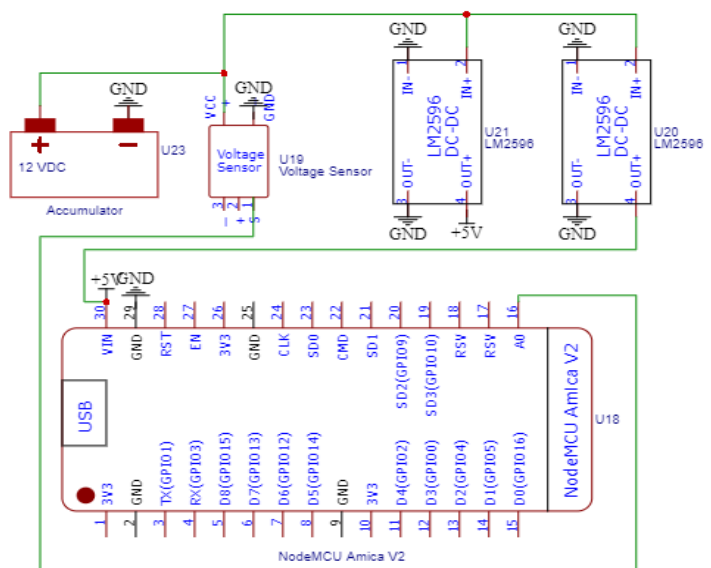

Gambar 12. Skema rangkaian sensor tegangan

Perhitungan persentase nilai error untuk mengetahui tingkat keakurasian antara pembacaan tegangan pada multimeter dan pembacaan tegangan pada aplikasi smartphone dapat dihitung dengan cara, yaitu:

$$
\frac{(\text { Pem.Multimeter })-(\text { Pem. Aplikasi Smartphone })}{(\text { Pembacaan Multimeter })} \times 100 \%
$$

Perhitungan selisih persentase secara keseluruhan dapat dilihat pada Tabel 2, sebagai berikut.

Tabel 2. pengujian pembacaan sensor tegangan

\begin{tabular}{|c|c|c|c|}
\hline \multirow{2}{*}{$\begin{array}{l}\text { Pengujian } \\
\text { Ke- }\end{array}$} & \multicolumn{2}{|c|}{$\begin{array}{c}\text { Pembacaan sensor tegangan } \\
\text { Vin (Volt) }\end{array}$} & \multirow{2}{*}{$\begin{array}{c}\text { Nilai } \\
\text { Error } \\
(\%)\end{array}$} \\
\hline & Multimeter & $\begin{array}{c}\text { Aplikasi } \\
\text { Smartphone }\end{array}$ & \\
\hline 1 & 12,68 & 12,60 & 0,65 \\
\hline 2 & 12,51 & 12,41 & 0,79 \\
\hline 3 & 12.41 & 12.34 & 0,56 \\
\hline 4 & 12.37 & 12.30 & 0,56 \\
\hline 5 & 12.31 & 12.24 & 0,56 \\
\hline
\end{tabular}

\subsubsection{Pengujian NodeMCU}

Pengujian NodeMCU bertujuan untuk mengetahui jarak komunikasi atau pertukaran data antara NodeMCU dan aplikasi smartphone. Pengujian dilakukan dengan cara mengirim perintah sebanyak 5 (lima) kali untuk masing-masing jarak yang telah ditentukan dengan menggunakan dua kondisi yaitu kondisi tanpa penghalang dan dengan penghalang.
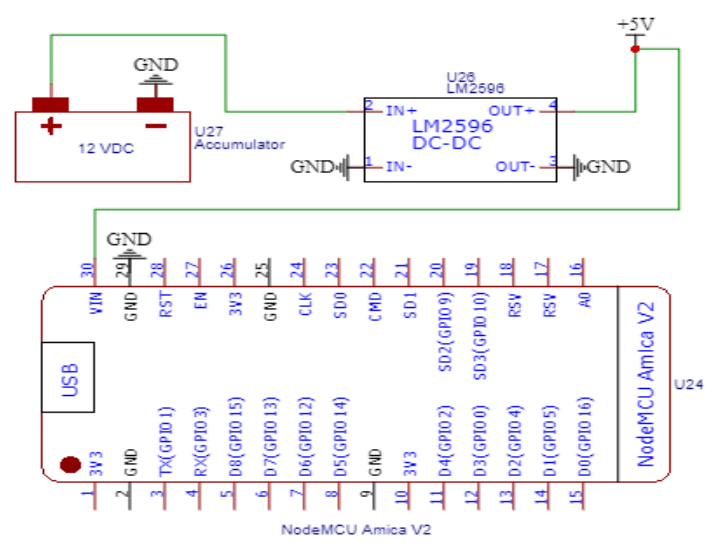

Gambar 13. Skema rangkaian NodeMCU

Tabel 3. Pengujian NodeMCU

\begin{tabular}{|c|c|c|c|c|c|c|c|c|c|}
\hline \multirow[t]{2}{*}{ No. } & \multirow[t]{2}{*}{ Pengujian } & \multicolumn{8}{|c|}{$\begin{array}{l}\text { Jarak komunikasi remot } \\
\text { dengan kursi roda elektrik } \\
\text { (Meter) }\end{array}$} \\
\hline & & 5 & 10 & 15 & 20 & 25 & 30 & 35 & 40 \\
\hline \multirow{5}{*}{1.} & \multirow{5}{*}{$\begin{array}{c}\text { Tanpa } \\
\text { Penghalang }\end{array}$} & $\sqrt{ }$ & $\sqrt{ }$ & $\sqrt{ }$ & $\sqrt{ }$ & $\sqrt{ }$ & $\sqrt{ }$ & $\sqrt{ }$ & - \\
\hline & & $\sqrt{ }$ & $\sqrt{ }$ & $\sqrt{ }$ & $\sqrt{ }$ & $\sqrt{ }$ & $\sqrt{ }$ & $\sqrt{ }$ & - \\
\hline & & $\sqrt{ }$ & $\sqrt{ }$ & $\sqrt{ }$ & $\sqrt{ }$ & $\sqrt{ }$ & $\sqrt{ }$ & $\sqrt{ }$ & - \\
\hline & & $\sqrt{ }$ & $\sqrt{ }$ & $\sqrt{ }$ & $\sqrt{ }$ & $\sqrt{ }$ & $\sqrt{ }$ & $\sqrt{ }$ & - \\
\hline & & $\sqrt{ }$ & $\sqrt{ }$ & $\sqrt{ }$ & $\sqrt{ }$ & $\sqrt{ }$ & $\sqrt{ }$ & $\sqrt{ }$ & - \\
\hline \multirow{5}{*}{2.} & \multirow{5}{*}{$\begin{array}{c}\text { Dengan } \\
\text { Penghalang }\end{array}$} & $\sqrt{ }$ & $\sqrt{ }$ & $\sqrt{ }$ & $\sqrt{ }$ & $\sqrt{ }$ & $\sqrt{ }$ & - & - \\
\hline & & $\sqrt{ }$ & $\sqrt{ }$ & $\sqrt{ }$ & $\sqrt{ }$ & $\sqrt{ }$ & $\sqrt{ }$ & - & - \\
\hline & & $\sqrt{ }$ & $\sqrt{ }$ & $\sqrt{ }$ & $\sqrt{ }$ & $\sqrt{ }$ & $\sqrt{ }$ & - & - \\
\hline & & $\sqrt{ }$ & $\sqrt{ }$ & $\sqrt{ }$ & $\sqrt{ }$ & $\sqrt{ }$ & $\sqrt{ }$ & - & - \\
\hline & & $\sqrt{ }$ & $\sqrt{ }$ & $\sqrt{ }$ & $\sqrt{ }$ & $\sqrt{ }$ & $\sqrt{ }$ & - & - \\
\hline
\end{tabular}


Tujuan pengujian ini untuk mengetahui jarak jangkauan maksimum antara NodeMCU yang sudah terpasang pada kursi roda elektrik dengan remot kontrol pada smartphone. Dan juga dapat mengetahui tingkat keberhasilan kursi roda menerima data yang dikirim oleh remot kontrol pada smartphone.
Gambar 14. Skema rangkaian sensor tegangan, relay, dan motor DC

Pada pengiriman data dari aplikasi android pada Tabel 4 meliputi pengujian pergerakan kursi roda elektrik bergerak maju, mundur, putar kiri, putar kanan dan berhenti, pengujian

Tabel 4. Pengujian pengiriman data pergerakan kursi roda

\begin{tabular}{|c|c|c|c|c|c|c|c|c|c|c|c|}
\hline \multirow{2}{*}{ No } & \multirow{2}{*}{$\begin{array}{c}\text { Jarak } \\
\text { (Meter) }\end{array}$} & \multicolumn{2}{|c|}{ Maju } & \multicolumn{2}{c|}{ Mundur } & \multicolumn{2}{c|}{ Putar Kanan } & \multicolumn{2}{c|}{ Putar Kiri } & \multicolumn{2}{c|}{ Berhenti } \\
\hline 1 & 10 & YA & 0.1 & YA & 0.1 & YA & 0.1 & YA & 0.1 & YA & 0.1 \\
\hline 2 & 10 & YA & 0.1 & YA & 0.1 & YA & 0.1 & YA & 0.1 & YA & 0.1 \\
\hline 3 & 10 & YA & 0.1 & YA & 0.1 & YA & 0.1 & YA & 0.1 & YA & 0.1 \\
\hline 4 & 10 & YA & 0.1 & YA & 0.1 & YA & 0.1 & YA & 0.1 & YA & 0.1 \\
\hline 5 & 10 & YA & 0.1 & YA & 0.1 & YA & 0.1 & YA & 0.1 & YA & 0.1 \\
\hline 6 & 10 & YA & 0.1 & YA & 0.1 & YA & 0.1 & YA & 0.1 & YA & 0.1 \\
\hline 7 & 10 & YA & 0.1 & YA & 0.1 & YA & 0.1 & YA & 0.1 & YA & 0.1 \\
\hline 8 & 10 & YA & 0.1 & YA & 0.1 & YA & 0.1 & YA & 0.1 & YA & 0.1 \\
\hline 9 & 10 & YA & 0.1 & YA & 0.1 & YA & 0.1 & YA & 0.1 & YA & 0.1 \\
\hline 10 & 10 & YA & 0.1 & YA & 0.1 & YA & 0.1 & YA & 0.1 & YA & 0.1 \\
\hline
\end{tabular}

\subsubsection{Pengujian Aplikasi Android}

Pengujian kali ini bertujuan untuk memastikan pengiriman data dari aplikasi android ke alat dan berapa lama waktu yang dibutuhkan untuk alat menerima data dari aplikasi android pada smartphone ini. Data yang dimaksud adalah data yang nantinya memerintahkan kursi roda elektrik ini melakukan pergerakan maju, mundur, putar kiri, putar kanan dan berhenti. Bukan hanya mengirim data, tapi aplikasi ini juga menerima data dari sensor tegangan untuk mengetahui status jumlah tegangan pada kursi roda.

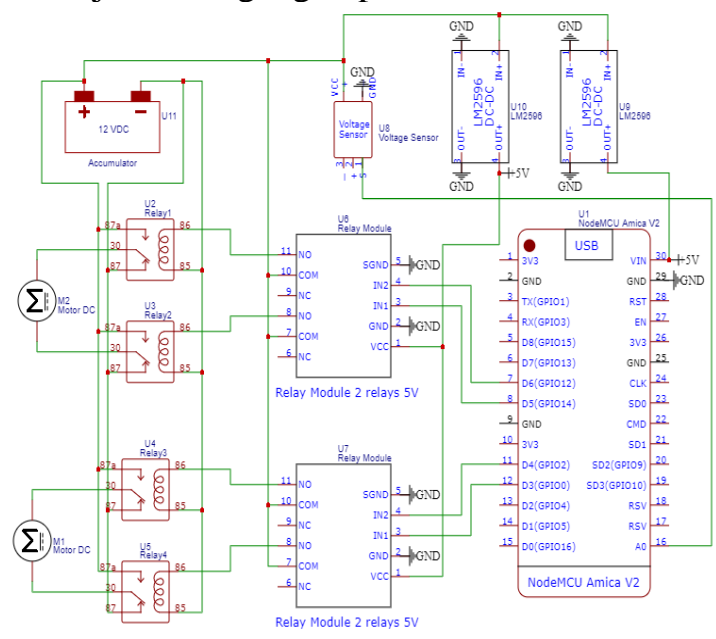

dilakukan sebanyak 10 (sepuluh) kali, sedangkan pengujian penerima data dari kursi roda ke aplikasi android pada Tabel 5 meliputi data pembacaan sensor tegangan pada aplikasi android.

Tabel 5. Pengujian penerimaan data aplikasi android

\begin{tabular}{|c|c|c|c|}
\hline \multirow{2}{*}{ No } & \multirow{2}{*}{$\begin{array}{c}\text { Jarak } \\
\text { (Meter) }\end{array}$} & \multicolumn{2}{|c|}{$\begin{array}{c}\text { Pembacaan tegangan pada aplikasi } \\
\text { android }\end{array}$} \\
\cline { 3 - 4 } & & Berhasil & Waktu (Detik) \\
\hline 1 & 10 & YA & 1 \\
\hline 2 & 10 & YA & 1 \\
\hline 3 & 10 & YA & 1 \\
\hline 4 & 10 & YA & 2 \\
\hline 5 & 10 & YA & 1 \\
\hline 6 & 10 & YA & 2 \\
\hline 7 & 10 & YA & 1 \\
\hline 8 & 10 & YA & 1 \\
\hline 9 & 10 & YA & 1 \\
\hline 10 & 10 & YA & 1 \\
\hline
\end{tabular}

\subsubsection{Pengujian Secara Keseluruhan}

Pengujian ini dilakukan untuk mengetahui kemampuan kursi roda elektrik dalam melakukan mobilitas. Dalam pengujian ini menggunakan 2 (dua) kondisi yaitu kondisi kursi roda tanpa beban dan kondisi kursi roda dengan beban. 
Perhitungan kecepatan rata-rata kursi roda elektrik merupakan hasil pembagian antara besaran jarak dengan besaran waktu tempuh. Sebagai contoh perhitungan kecepatan
Penyelesaian:

$\mathrm{V}=5 / 3.38$

$\mathrm{V}=0.79 \mathrm{~m} / \mathrm{detik}$

Tabel 6. Pengujian secara keseluruhan

\begin{tabular}{|c|c|c|c|c|c|c|}
\hline No. & Percobaan & $\begin{array}{c}\text { Perintah } \\
\text { Pergerakan }\end{array}$ & $\begin{array}{c}\text { Jarak } \\
\text { (Meter) }\end{array}$ & $\begin{array}{l}\text { Waktu } \\
\text { tempuh } \\
\text { (Detik) }\end{array}$ & $\begin{array}{l}\text { Berat Beban } \\
\quad(\mathrm{Kg})\end{array}$ & $\begin{array}{c}\text { Kecepatan } \\
\text { (m/detik) }\end{array}$ \\
\hline \multirow{4}{*}{1.} & \multirow{4}{*}{$\mathrm{Ke}-1$} & Maju & 5 & 3.38 & 0 & 1.47 \\
\hline & & Mundur & 5 & 3.54 & 0 & 1.41 \\
\hline & & Kiri & 1 & 1.42 & 0 & 0,70 \\
\hline & & Kanan & 1 & 1.35 & 0 & 0.74 \\
\hline \multirow{4}{*}{2.} & \multirow{4}{*}{$\mathrm{Ke}-2$} & Maju & 5 & 3.48 & 10 & 1.43 \\
\hline & & Mundur & 5 & 3.79 & 10 & 1,31 \\
\hline & & Kiri & 1 & 1.55 & 10 & 0.64 \\
\hline & & Kanan & 1 & 1.67 & 10 & 0.59 \\
\hline \multirow{4}{*}{3.} & \multirow{4}{*}{$\mathrm{Ke}-3$} & Maju & 5 & 4.26 & 20 & 1.17 \\
\hline & & Mundur & 5 & 4.89 & 20 & 1.02 \\
\hline & & Kiri & 1 & 1.86 & 20 & 0.53 \\
\hline & & Kanan & 1 & 2.04 & 20 & 0,49 \\
\hline \multirow{4}{*}{4.} & \multirow{4}{*}{$\mathrm{Ke}-4$} & Maju & 5 & 6.28 & 30 & 0.79 \\
\hline & & Mundur & 5 & 5.48 & 30 & 0.91 \\
\hline & & Kiri & 1 & 2.16 & 30 & 0,46 \\
\hline & & Kanan & 1 & 2.42 & 30 & 0.41 \\
\hline \multirow{4}{*}{5.} & \multirow{4}{*}{$\mathrm{Ke}-5$} & Maju & 5 & - & 40 & - \\
\hline & & Mundur & 5 & - & 40 & - \\
\hline & & Kiri & 1 & - & 40 & - \\
\hline & & Kanan & 1 & - & 40 & - \\
\hline
\end{tabular}

rata-rata kursi roda elektrik tanpa menggunakan beban dengan kondisi perintah maju, sebagai berikut:

$$
\begin{aligned}
& \mathrm{V}=\mathrm{s} / \mathrm{t} \\
& \text { Diketahui: } \\
& \mathrm{s}=5 \\
& \mathrm{t}=3.38
\end{aligned}
$$

Ditanyakan:

$\mathrm{V}=$ $\mathrm{m} / \mathrm{detik}$

Penyelesaian:

$\mathrm{V}=5 / 3.38$

$\mathrm{V}=1.47 \mathrm{~m} /$ detik

Perhitungan kecepatan rata-rata kursi roda elektrik dengan menggunakan beban 30 $\mathrm{kg}$ dengan kondisi perintah maju, sebagai berikut:

$$
\begin{aligned}
& \mathrm{V}=\mathrm{s} / \mathrm{t} \\
& \text { Diketahui: } \\
& \mathrm{s}=5 \\
& \mathrm{t}=6.28
\end{aligned}
$$

Ditanyakan:

$\mathrm{V}=$ .m/detik
Pengujian kecepatan rata-rata secara keseluruhan dapat dilihat pada Tabel 6 , sebagai berikut.

\subsection{Pembahasan}

Rancang bangun kursi roda elektrik berbasis Internet of Things (IoT) merupakan alat mobilitas yang telah dilengkapi dengan sensor tegangan, relay dan telah ditambahkan aplikasi remot kontrol pada smartphone. Sensor tegangan berfungsi untuk mengetahui jumlah tegangan pada kursi roda, relay berfungsi sebagai penyambung dan pemutus tegangan, sedangkan aplikasi remot kontrol pada smartphone digunakan sebagai kontrol pergerakan kursi roda. Kemudian data hasil pembacaan sensor tegangan akan dikirim ke aplikasi smartphone melalui board NodeMCU yang telah dilengkapi dengan modul WiFi.

Adapun beberapa prinsip kerja dari kursi roda ini, yaitu : 
1. Sensor tegangan akan membaca tegangan pada kursi roda dan mengirim data tersebut ke aplikasi smartphone.

2. Aplikasi remot kontrol pada smartphone berfungsi untuk mengontrol pergerakan kursi roda.

\subsubsection{Analisa keberhasilan pengujian tegangan catu daya motor DC}

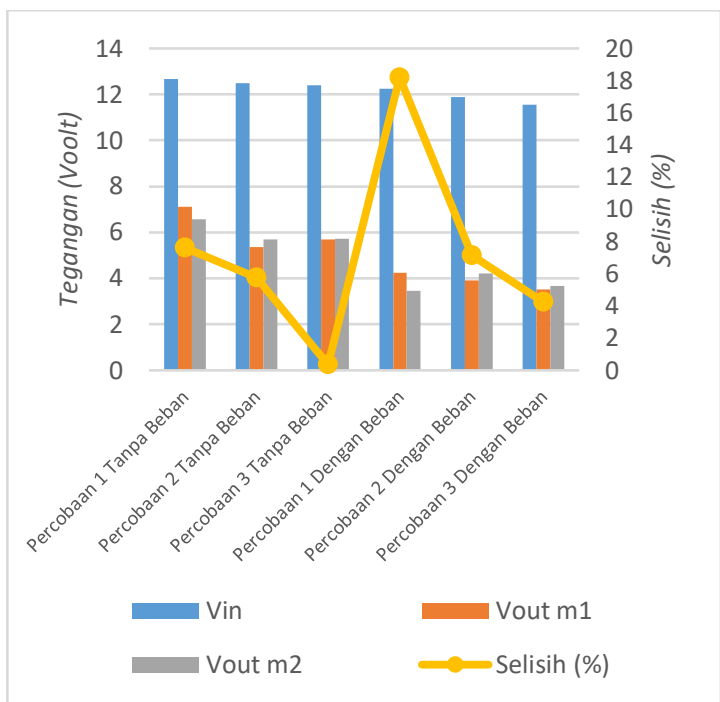

Gambar 15. Grafik tegangan catu daya motor

$$
\text { DC }
$$

Gambar 4.12 menunjukkan grafik hasil pengukuran Vout motor DC dengan selisih presentasi (\%) antara motor kanan dan motor kiri, dalam percobaan ini dilakukan 3 (tiga) kali percobaan tanpa beban dan 3 (tiga) kali dengan beban.

Dari data grafik hasil pengujian dapat dilihat konsumsi tegangan motor DC kanan dan motor DC kiri berfariasi, dan pengukuran catu daya motor dengan beban membutuhkan tegangan lebih besar dibandingkan tanpa beban, sehingga dibutuhkan motor DC yang mempunyai konsumsi daya kecil.

\subsubsection{Analisa keberhasilan pengujian pembacaan sensor tegangan}

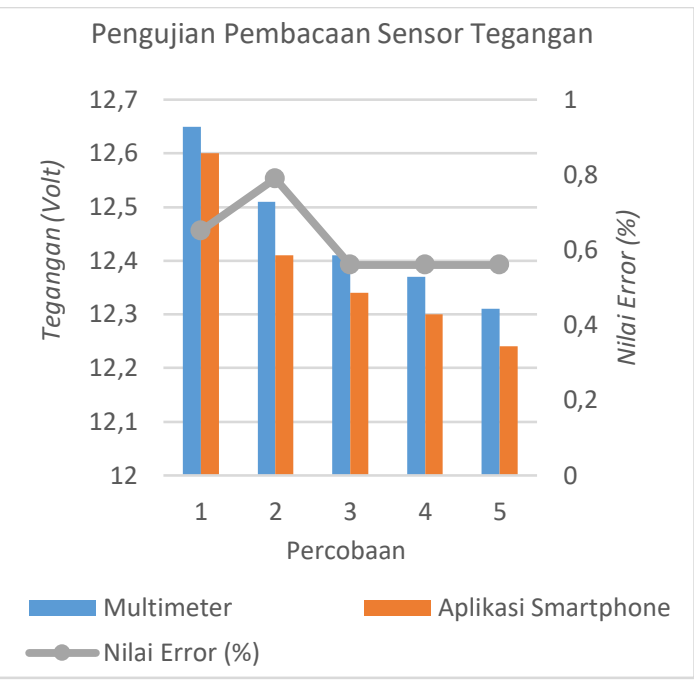

Gambar 16. Grafik pembacaan sensor tegangan

Gambar 16 menunjukan perbandingan antara pembacaan tegangan secara manual menggunakan multimeter dan menggunakan sensor tegangan yang ditampilkan pada aplikasi smartphone, mempunyai persentasi tingkat akurasi yang cukup baik yang tidak terlalu jauh berbeda, pengujian ini dilakukan masing-masing 5 (lima) kali.

\subsubsection{Analisa keberhasilan pengujian NodeMCU}

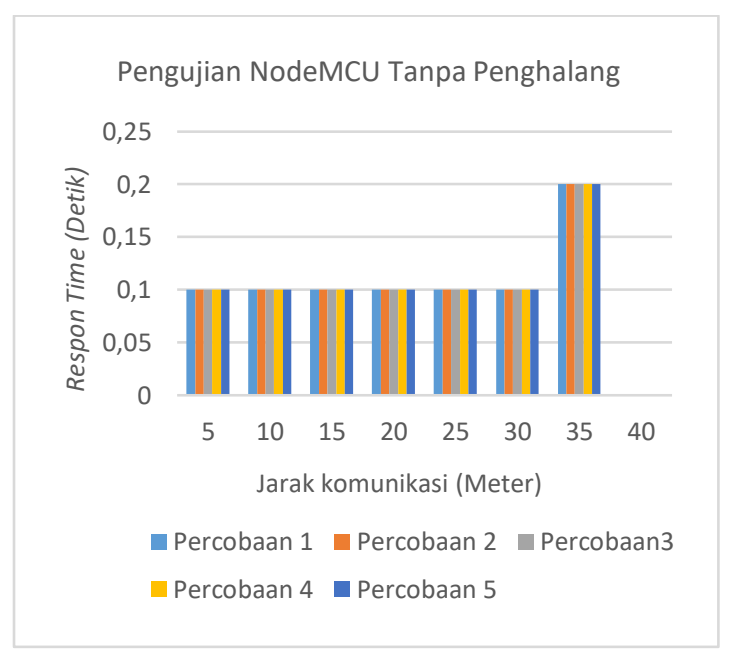

Gambar 17. Grafik pengujian NodeMCU tanpa penghalang 


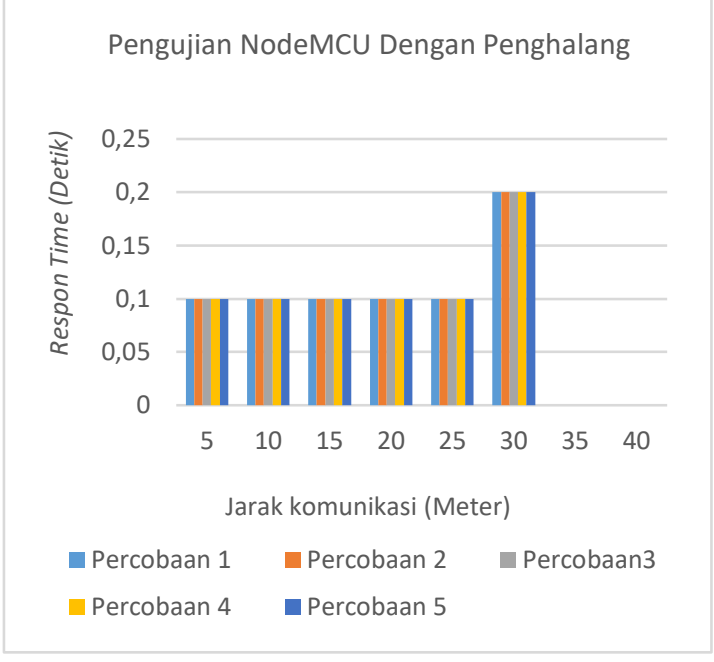

Gambar 18. Grafik pengujian NodeMCU dengan penghalang

Gambar 17 dan Gambar 18 menunjukkan perbandingan respond time terhadap jarak jangkauan antara smartphone dan kursi roda, pengujian ini dilakukan masing-masing 5 (lima) kali. Pengujian dilakukan dengan menempatkan kursi roda elektrik di area terbuka atau tanpa penghalang mempunyai komunikasi yang lebih luas dibandingkan pengujian di area tertutup atau dengan menggunakan penghalang.

\subsubsection{Analisa keberhasilan pengujian aplikasi android}

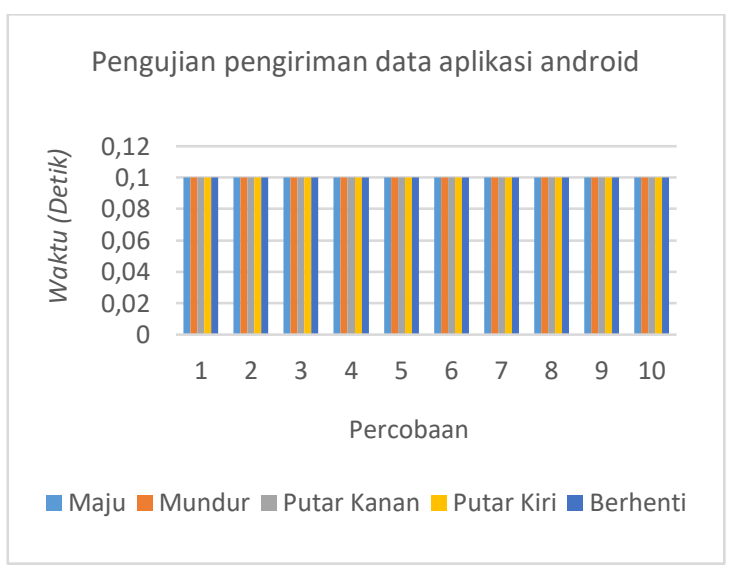

Gambar 19. Grafik pengiriman data dari aplikasi android

Gambar 19 menunjukkan pengiriman data dari aplikasi android terhadap kursi roda membutuhkan waktu rata-rata 0,1 detik, pengujian masing-masing dilakukan 10 (sepuluh) kali.

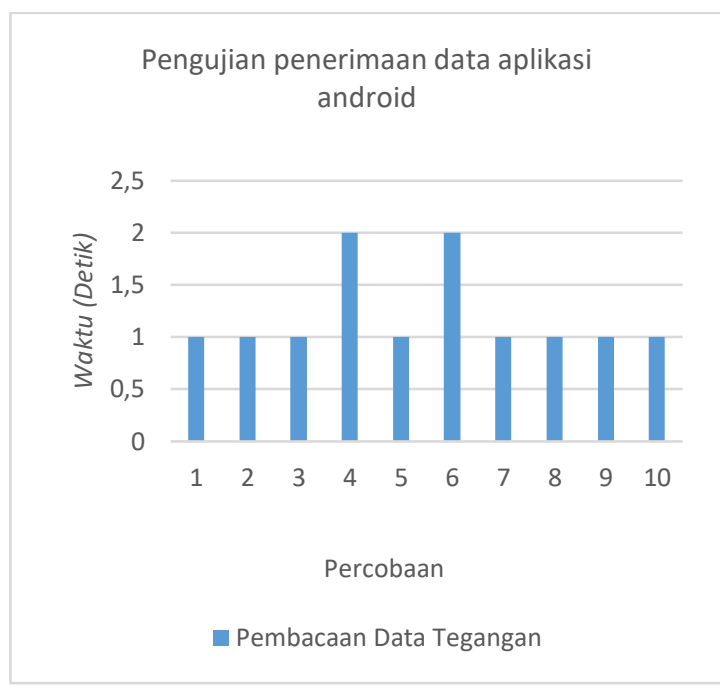

Gambar 20. Grafik penerimaan data dari aplikasi android

Gambar 4.20, menujukan penerimaan data tegangan membutuhkan waktu 1 sampai 2 detik, pengiriman data ini di pengaruhi oleh kecepatan pengiriman data secara real time, pengujian dilakukan 10 (sepuluh) kali.

\subsubsection{Analisa keberhasilan pengujian secara keseluruhan}

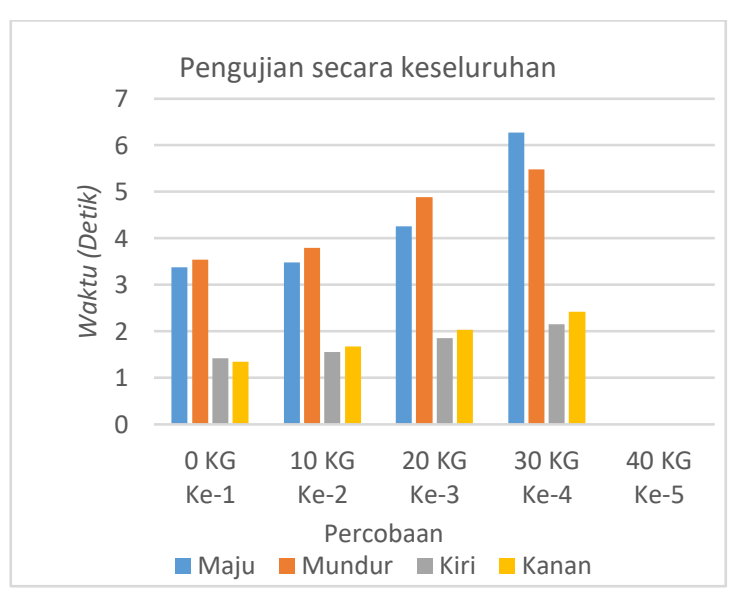

Gambar 21. Grafik pengujian secara keseluruhan

Dari Gambar 21, menujukan perbandingan waktu dengan jarak tempuh 5 (lima) meter dengan beban yang berbeda, pengujian ini dilakukan masing-masing 5 (lima) kali. 
Dalam kondisi kursi roda elektrik tanpa beban, kursi roda dapat melakukan mobilitas atau pergerakan dengan kecepatan 1,47 $\mathrm{m} /$ detik untuk arah maju, $1,41 \mathrm{~m} /$ detik untuk arah mundur, putar kiri $0,70 \mathrm{~m} /$ detik dan putar kanan 0,74 $\mathrm{m} /$ detik. Beban maksimal yang dapat dibawa oleh kursi roda adalah seberat 30 $\mathrm{kg}$, dengan kecepatan arah maju 0,79 m/detik, arah mundur $0,91 \mathrm{~m} /$ detik, putar kiri 0,46 $\mathrm{m} /$ detik dan putar kanan $0,41 \mathrm{~m} /$ detik.

\subsection{Kendala yang dihadapi selama penelitian}

Dalam melakukan penelitian ini, ada beberapa kendala yang dihadapi oleh penulis sehingga menghambat proses pengerjaannya. Kendala-kendala yang dihadapi oleh penulis tersebut adalah:

1. Pembacaan nilai tegangan modul voltage sensor sangat jauh berbeda dengan tegangan sebenarnya pada akumulator/aki ketika menggunakan program default pada NodeMCU, sehingga penulis melakukan penyesuaian nilai perhitungan $\mathrm{R}$ (resistor) pada program sehinggan hasil pembacaan nilai tegangan dari voltage sensor dapat mendekati nilai tegangan sebenarnya.

2. Motor DC yang digunakan mempunyai spesifikasi daya 300 watt/motor dengan tegangan kerja 12 VDC, dan pada penelitian ini menggunakan 2 (dua) motor DC, sehingga membutuhkan arus yang besar untuk menjalankan motor DC tersebut. Penulis menggunakan kabel dengan diameter yaitu $6 \mathrm{~mm}$, agar tidak terjadi panas yang berlebihan pada kabel.

3. Software Delphi XE8 untuk membuat aplikasi interface membutuhkan spesifikasi laptop yang tinggi agar pembuatan aplikasi dapat berjalan dengan baik.

4. Smartphone yang digunakan untuk mengoperasikan aplikasi juga harus mempunyai spesifikasi tinggi. Jika tidak, maka aplikasi sistem yang telah dibuat tidak akan berjalan dengan baik atau not responding (pada penelitian ini penulis menggunakan smartphone realme note 7).

\section{PENUTUP}

\subsection{Kesimpulan}

Berdasarkan hasil pengujian hardware dan software serta pengambilan data yang telah dilakukan pada penelitian dengan judul rancang bangun kursi roda elektrik berbasis Internet of Things (IoT), maka diperoleh beberapa kesimpulan diantaranya yaitu :

1. Perancangan kursi roda elektrik berbasis Internet of Things (IoT) ini menggunakan 2 (dua) buah motor DC sebagai penggerak kursi roda elektrik dan menggunakan 2 (dua) buah akumulator/aki 12 volt sebagai catu daya yang terhubung paralel.

2. Perancangan kursi roda elektrik berbasis Internet of Things (IoT) ini menggunakan sensor tegangan sebagai pembacaan data tegangan dan menggunakan aplikasi remot kontrol pada smartphone untuk mengontrol pergerakan kursi roda.

3. Proses pengiriman datanya melalui jaringan WiFi sehingga smartphone harus terkoneksi dengan kursi roda agar dapat dilakukan pengontrolan.

Kursi roda elektrik berbasis internet of things (IoT), memiliki unjuk kerja yaitu kursi roda dapat membawa beban maksimal sebesar $30 \mathrm{~kg}$ dengan kecepatan $0,79 \mathrm{~m} /$ detik, ditambah beban akumulator/aki dan motor DC $6,4 \mathrm{~kg}$, sehingga total keseluruhan beban yang dapat dibawah sebesar $36,4 \mathrm{~kg}$.

\subsection{Saran}

Dari berbagai uji coba yang telah dilakukan karena keterbatasan waktu, kemampuan, dan pengetahuan, masih banyak kekurangan dalam pengerjaan alat yang dibuat ini, sehingga penulis menambahkan beberapa saran agar kedepanya alat tersebut bisa lebih dikembangkan diantaranya berikut :

1. Menambahkan indikator untuk mengetahui kondisi baterai.

2. Menggunakan driver motor yang dapat sesuai dengan spesifikasi motor DC dan dapat mengatur kecepatan motor DC.

3. Menggunakan motor DC dengan konsumsi daya kecil dan torsi yang lebih besar. 


\section{DAFTAR PUSTAKA}

[1] Budiman Setyo Utomo. 2018. Kursi Roda Terkendali Otomatis Speech Recognition Dengan Bluetooth Berbasis Android. Fakultas Teknik Universitas Negeri Yogyakarta.

[2] Sahat Nelson, S. 2018. Rancang Bangun Simulasi Pengendali Kursi Roda Dengan Menggunakan Komunikasi Bluetooth Berbasis Arduino Nano. Fakultas MIPA Universitas Sumatra Utara. Medan.

[3] Affinannisa T. N. 2018. Simulator Kursi Roda Otomatis Dengan Sensor Flex Berbasis Mikrokontroler. Teknik Elektronika Universitas Negeri Yogyakarta.

[4] Husna Khairun Nisa. 2019. Rancang Bangun Sistem Kursi Roda Dengan Analog Joystick Dan Voice Kontrol Berbasis Respberry Pi. Fakultas Teknologi Informasi Dan Elektro Universitas Teknologi Yogyakarta.

[5] Silvia, S. 2019. Apa itu Internet of Thinks?, https://www.jetorbit.com/blog/apa-ituinternet-of-things/, diakses: 29 Maret 2020.

[6] Indra Cahyadi Nugraha. 2018. Rancang Bangun Pengendali Kursi Roda Menggunakan Sensor Ultrasonik Dan Motor DC Berbasis Android. Fakultas Teknologi Informasi Dan Elektro Universitas Teknologi Yogyakarta.

[7] Medicalogy. 2019.7 Ragam Kursi Roda, Unik dan Bermanfaat Untuk Segala Kondisi, https://www.medicalogy.com/blog/jenisjenis-kursi-roda/, diakses: 28 Maret 2020.

[8] Florus H, S. 2017. Sistem Data Logger Peralatan Elektronik Berbasis Android. Teknik Elektro Universitas Sanata Dharma.
[9] Budi kiswoyo. 2016. Pengertian dan macam-macam jenis relay, https://teknikelektronika.com/pengertian -relay-fungsi-relay/, diakses pada 27 Maret 2020.

[10] Fitriandi, Afrizal. 2016. Rancang Bangun alat monitoring arus dan tegangan berbasis mikrokontroler dengan SMS Gateway. Indonesia, Bandar Lampung, Universitas Lampung.

[11] Ajie, 2015. Membuat aplikasi anderoid dengan delphi XE8, http://saptaji.com/2015/07/18/membuataplikasi-android-dengan-delphi-xe8/. Diakses: 2 April 2020. 